Physiological and Morphological

Characterization of Basalt Milkvetch

(Astragalus filipes): Basis for Plant

Improvement

Kishor Bhattarai, Douglas A. Johnson, Thomas A. Jones, Kevin J. Connors, and Dale R. Gardner

Few legumes from North America are commercially available for use on semiarid rangelands of the western United States. Basalt milkvetch (Astragalus filipes) is a legume that is widely distributed in western North America and holds promise for revegetation, reclamation, and restoration. Seeds from 67 locations throughout six western states were collected, seedlings were transplanted to two sites in northern Utah, and plants were evaluated for various physiological and morphological characteristics. Results provide important data for identifying basalt milkvetch collections that have the greatest potential for use on degraded rangelands.
Perceptions of Texas Landowners Regarding Fire and Its Use

Urs P. Kreuter, J. Brad Woodard, Charles A. Taylor, and W. Richard Teague

Periodic fire is a historical element of many rangelands, but landowners are frequently reluctant to burn their land because they perceive it to be a dangerous or wasteful practice. We report the results of a survey evaluating perceptions of fire use for 785 landowners in six Texas counties. Reasons respondents did not apply fire included lack of resources, assistance with burn plan development, and legal concerns, while members of the Edwards Plateau Prescribed Burning Association viewed prescribed fire more positively. Our study suggests that the application of prescribed fire on privately owned land could be increased through the formation of prescribed burning associations.

\title{
Erratum
}

\section{Wooley, S. C., S. Walker, J. Vernon, and R. L. Lindroth. 2008. Aspen Decline, Aspen Chemistry, and Elk Herbivory: Are They Linked? Rangelands 30(1):17-21.}

In this article, $r$ values in Table 1 should be preceded by negative signs. The primary author regrets the error. The corrected table is shown below.

Table 1. Simple linear regression results explaining the relationship of total consumption (g) or leaf consumption (g) in relation to the foliar concentration of phenolic glycosides and condensed tannins

\begin{tabular}{|l|c|c|c|c|}
\hline & \multicolumn{2}{|c|}{ Total consumption } & \multicolumn{2}{c|}{ Leaf consumption } \\
\hline Salicortin & $\boldsymbol{r}$ & $\boldsymbol{P}$ & $\boldsymbol{r}$ \\
\hline Tremulacin & -0.68 & 0.207 & -0.95 & 0.014 \\
\hline Total phenolic glycosides* & -0.61 & 0.279 & -0.89 & 0.045 \\
\hline Condensed tannins & -0.65 & 0.235 & -0.92 & 0.024 \\
\hline *Total phenolic glycosides are the sum of the concentration of salicortin and tremulacin. & 0.375 \\
\hline
\end{tabular}

